\title{
Psychology: a reality check
}

\author{
If clinical psychology in the United States wants to remain viable and relevant in today's health systems, \\ it needs to publicly embrace science.
}

$\Lambda$ nyone reading Sigmund Freud's original works might well be seduced by the beauty of his prose, the elegance of his arguments and the acuity of his intuition. But those with a grounding in science will also be shocked by the abandon with which he elaborated his theories on the basis of essentially no empirical evidence. This is one of the main reasons why Freudian-style psychoanalysis has long since fallen out of fashion: its huge expense - treatment can stretch over years - is not balanced by evidence of efficacy.

Clinical psychology at least has its roots in experimentation, but it is drifting away from science. Concerns about cost-benefit issues are growing, especially in the United States. According to a damning report published last week (T. B. Baker et al. Psychol. Sci. Public Interest $9,67-103 ; 2008)$, an alarmingly high proportion of practitioners consider scientific evidence to be less important than their personal - that is, subjective - clinical experience.

The irony is that, during the past 20 years, science has made great strides in directions that could support clinical psychology - in neuroimaging, for example, as well as molecular and behavioural genetics, and cognitive neuroscience. Numerous psychological interventions have been proved to be both effective and relatively cheap. Yet many psychologists continue to use unproven therapies that have no clear outcome measures - including, in extreme cases, such highly suspect regimens as 'dolphin-assisted therapy'.

The situation has created tensions within the American Psychological Association (APA), the body that accredits the courses leading to qualification for a clinical psychologist to practise in the United States and Canada. The APA requires that such courses have a scientific component, but it does not require that science be as central as some members would like. In frustration, representatives of some twodozen top research-focused graduate-training programmes grouped together in 1994 to form the Academy of Psychological Clinical Science (APCS), with a mission to promote scientific psychology.
The APCS effort has not been enough to change attitudes among all practitioners. But, in the United States, political pressure for change is building rapidly. The debates swirling around health-care reform have made it clear that key decision-makers expect medical caregivers to justify their therapies in terms of proven cost-effectiveness. If clinical psychologists cannot do this plausibly, they will be marginalized.

A quick and effective way to break this impasse would be to create a US version of the system that transformed clinical psychology (and medical practice generally) in England and Wales. There, the National
"There is a moral imperative to turn psychology into a robust and valued science." Institute for Health and Clinical Excellence (NICE) evaluates therapies for evidence of efficacy, and approves the ones to be covered by the state health system (see Nature 461, 336-339; 2009). Private health insurers are influenced by NICE's decisions, and any clinical psychologist wishing to offer dolphin-assisted therapy in Britain will be hard-pushed to find patients.

For many opponents of health-care reform in the United States, however, NICE represents the epitome of big-government intrusion into individual freedom of choice; it remains to be seen whether such a body can ever be created in America. Still, as Baker et al. point out, interested US psychologists could take matters into their own hands by establishing a new accreditation system for scientifically trained psychologists in parallel with the APA system.

The APCS is well-positioned to take such a step. But whoever takes it should do so soon. Unmet mental-health needs are massive and growing: the number of Americans receiving mental-health care has almost doubled in the past 20 years. There is a moral imperative to turn the craft of psychology - in danger of falling, Freud-like, out of fashion - into a robust and valued science informed by the best available research and economic evidence.

it in February in the \$787-billion stimulus bill.

Indeed, Obama has made the promotion of science and technology - and evidence-based decision-making - a frequent theme of his young presidency, and most US researchers consider this a refreshing contrast to the previous administration. But they would be wise to remind themselves that Congress, not the president, is in charge of most of the key issues affecting American research. And in particular, the stimulus money that Congress has funnelled into science this year and next has the potential to create a long-term problem.

In the short term, the stimulus bill passed last February has poured billions of dollars into the research agencies (see page 856), with the largest chunk going to the Department of Energy for much-needed programmes in energy efficiency, environmental clean-up and research. At other agencies, such as the NIH and the National Science
$(\mathrm{NIH})$ in Bethesda, Maryland, to announce that the agency had distributed half of the extra US $\$ 10.4$ billion that Congress awarded 